\title{
Current techniques in adult-acquired buried penis repair: where are we now
}

\author{
Katherine M. Theisen ${ }^{1}$, Ashley V. Alford ${ }^{1}$, Nicholas Kim² ${ }^{2}$ Joseph J. Pariser ${ }^{1}$ \\ 'Department of Urology, University of Minnesota, Minneapolis, MN 55455, USA. \\ ${ }^{2}$ Department of Plastic Surgery, University of Minnesota, Minneapolis, MN 55455, USA. \\ Correspondence to: Dr. Joseph J. Pariser, Department of Urology, University of Minnesota, Minneapolis, MN 55455, USA. \\ E-mail: jpariser@umn.edu
}

How to cite this article: Theisen KM, Alford AV, Kim N, Pariser JJ. Current techniques in adult acquired buried penis repair: where are we now. Plast Aesthet Res 2020;7:56. http://dx.doi.org/10.20517/2347-9264.2020.83

Received: 16 Apr 2020 First Decision: 15 May 2020 Revised: 19 May 2020 Accepted: 19 Jun 2020 Published: 21 Oct 2020

Academic Editor: Marlon E. Buncamper, Stan J. Monstrey Copy Editor: Jing-Wen Zhang Production Editor: Jing Yu

\begin{abstract}
Adult-acquired buried penis (AABP) is a condition associated with penile entrapment, penile shaft skin loss, and an enlarged pannus which engulfs the penis. The increased prevalence, awareness, and availability of surgical repair have led to a relative standardization in repairs. The surgical approach to AABP has evolved from a lengthy procedure with extended inpatient stay to one that may be done in an outpatient setting. The critical steps for surgical management of AABP have remained largely consistent over time, including: release of the penis with removal of diseased skin, suprapubic and/or abdominal panniculectomy, and skin coverage (usually with grafts). In contrast, the finer points of the procedure and perioperative care have undergone evolution. The aim of our approach was to optimize postoperative aesthetic and functional outcomes. Our perioperative management was modeled after enhanced recovery after surgery principles to minimize morbidity and expedite recovery. There remains room for improvement in the care of individuals with AABP, specifically multi-institutional collaboration, development of disease-specific outcome measures, and standardization of treatment algorithms.
\end{abstract}

Keywords: Buried penis, morbidity, surgical algorithms, postoperative period, quality of life

\section{INTRODUCTION}

Individuals with adult-acquired buried penis (AABP) are increasingly seeking care due to the increasing rates of obesity in the United States ${ }^{[1]}$ and to an increase in the number of centers that offer surgical

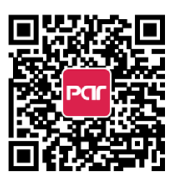






Figure 1. The condition of adult-acquired buried penis presents on a spectrum of severity

treatment for this condition. Early series describing surgical approaches in the management of AABP involved a relatively long procedure with prolonged postoperative bed rest and lengthy hospital stays ${ }^{[2-4]}$. "Success" of an operation was predominantly defined by surgeon-specific objective measures of success, while patient-related quality of life measures were not considered until more recently ${ }^{[5-7]}$. Much like many other operations in the field of urology (e.g., transurethral resection of the prostate, radical prostatectomy, and urethroplasty), the surgical approach to AABP has undergone a rapid evolution to minimize morbidity and expedite discharge from the hospital. However, some variation in treatment and postoperative care still exists. The purpose of this article is to describe the maturation of surgical approaches for this condition, describe our enhanced recovery after surgery (ERAS)-inspired approach for postoperative care, and make a plea for improved collaboration amongst surgeons to reduce the variability in care for this population.

\section{EVOLUTION OF DISEASE MANAGEMENT}

The early approach to AABP management was modeled after the treatment of concealed penis in pediatric patients. This quickly evolved as surgeons began to realize that the etiology and anatomy of buried penis in adulthood differs from that seen in childhood ${ }^{[2,8]}$. It became increasingly apparent that aggressive surgical resection of diseased penile skin with suprapubic/abdominal lipectomy was needed to prevent re-burying ${ }^{[3,9,10]}$. Therefore, the surgical approach to AABP was modified to more closely resemble the surgical approach utilized for genital lymphedema that had been described as early as the 1800 s and refined between the 1930s-1980s ${ }^{[11,12]}$.

With more experience treating this condition, surgeons have come to appreciate that AABP falls on a spectrum of severity [Figure 1] and that precise surgical techniques must be tailored to each individual patient. Several classification systems and treatment algorithms have been devised to promote a protocolized and stepwise approach to surgical intervention ${ }^{[13-15]}$. Despite variations across the different classification systems, the critical factors utilized to properly plan a surgical approach include: assessment of penile skin viability after it is released, determining the degree to which the escutcheon and/or pannus contribute to penile burying, and evaluation for concomitant scrotal lymphedema, which may need to be resected.

\section{Surgical steps - release of the buried penis}

One feature that is commonly ascribed to the pathophysiology of AABP is abnormal attachments of the penile dartos fascia to Buck's fascia such that penile skin - under downward pressure from abdominal adiposity - slides over the head of the penis. Therefore, early series focused on re-establishing the penopubic and penoscrotal angles after simply removing the cicatrix that trapped the penis; the rest of the penile skin was not resected. Angles were re-established using tacking sutures placed between the subdermis of the proximal penile skin and the tunica albuginea dorsally and ventrally ${ }^{[3,8]}$. However, there was some concern that leaving most of the penile skin behind was leading to high re-bury rates ${ }^{[3,14]}$. Therefore, it became 


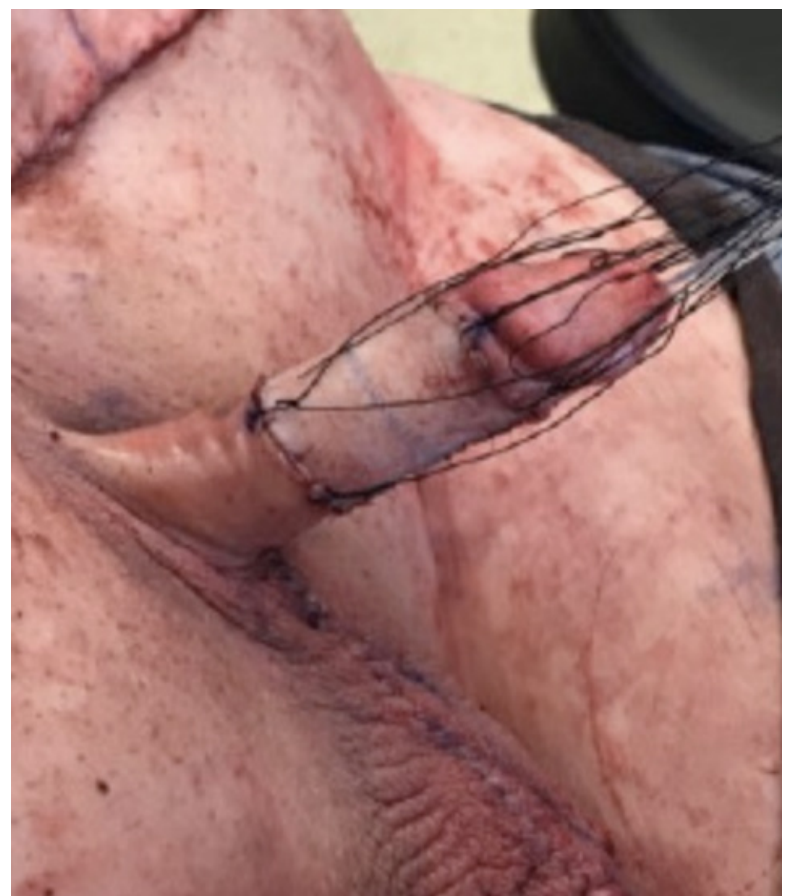

Figure 2. Remnant of healthy penile skin at the base of the penis with full-thickness graft covering the skin defect on the distal penile shaft

commonplace to remove all penile skin with the hope of achieving better long-term success ${ }^{[16,17]}$, similar to the approach for genital lymphedema ${ }^{[12]}$.

Penile skin defects were then covered with local skin flaps or grafts. Local skin flaps fell out of favor as scrotal rugae and hair bearing skin tended to result in poorer cosmetic outcomes ${ }^{[18]}$. Free skin grafts have long been a common adjunct to surgical correction of AABP. An early series in the plastic surgery literature utilized full thickness skin grafts from the abdominal pannus ${ }^{[10]}$. However, split-thickness skin grafts have become the modality of choice in the urologic literature ${ }^{[5,6,13,16,17,19-22]}$. Split-thickness skin grafts have the advantage of maximizing graft take rates, while being universally available (usually from the thigh). More recently, there has been renewed interest in full-thickness grafts because of the benefits of decreasing secondary graft contracture and improving cosmesis (both from a graft perspective and the ability to avoid a thigh scar by harvesting from the escutcheon $)^{[23]}$.

Our approach has become a hybrid of multiple techniques. In our experience, we have found that preservation of some healthy penile skin can improve cosmetic outcomes. We save as much viable penile skin as possible and aggressively re-establish the penopubic and penoscrotal angles with suprapubic lipectomy and tacking sutures between the skin and base of the penis. We leave a "skin bridge" at the superior base of the penis which is tacked to the fascia overlying the pubic symphysis. Remaining penile skin defects are preferentially covered with full-thickness skin grafts from an area of the escutcheon or pannus specimen relatively devoid of hair [Figure 2].

We utilize split-thickness grafts when graft take is a concern or when there is too little skin available from the escutcheon/pannus specimen to obtain a full-thickness graft. We use fibrin sealant to aid graft take ${ }^{[24]}$. We cover penile skin grafts with a bolster dressing composed of a layer of Vaseline gauze, a thick layer of Kling gauze, and a thin final layer of Coban. Bolster dressings are commonly utilized after penile skin grafting, but some groups prefer to use negative pressure wound therapy $(\mathrm{VAC})^{[6,25]}$. No randomized trials 
Table 1. Variability in the intraoperative, perioperative, and postoperative management of patients undergoing surgical repair of adult-acquired buried penis

\begin{tabular}{|c|c|c|c|c|c|}
\hline Series & $\begin{array}{c}\text { Graft } \\
\text { preference }\end{array}$ & $\begin{array}{c}\text { Graft } \\
\text { management }\end{array}$ & $\begin{array}{c}\text { Post-operative bedrest after } \\
\text { skin graft }\end{array}$ & $\begin{array}{l}\text { VTE prophylaxis on } \\
\text { discharge }\end{array}$ & $\begin{array}{l}\text { Antibiotics } \\
\text { on discharge }\end{array}$ \\
\hline Donatucci and Ritter 1998 & STSG & Bolster dressing & 6 days & No & No \\
\hline Tang et al. ${ }^{[3]} 2008$ & STSG & Bolster dressing & 3 days & No & 14 days \\
\hline Rybak et al. ${ }^{[5]} 2014$ & STSG & Bolster dressing & Not specified & No & No \\
\hline Voznesensky et al. ${ }^{[6]} 2017$ & STSG & Wound VAC & 2 days & No & No \\
\hline Pariser et al. ${ }^{[13]} 2018$ & STSG & Bolster dressing & 2 days & $\begin{array}{l}\text { Apixiban } 2.5 \text { mg PO BID, } 30 \\
\text { days }\end{array}$ & No \\
\hline Monn et al. ${ }^{[23]} 2019$ & FTSG & Bolster dressing & Not specified & No & No \\
\hline Cocciet al. ${ }^{[39]} 2019$ & STSG & Bolster dressing & Not specified & No & No \\
\hline Theisen et al. ${ }^{[7]} 2018$ & STSG & Bolster dressing & 2 days & No & 14 days \\
\hline Strother et al. ${ }^{[26]} 2018$ & STSG & Wound VAC & $\begin{array}{l}\text { 3-5 days (up to chair, no } \\
\text { ambulation) }\end{array}$ & No & No \\
\hline Hampson et al. ${ }^{[22]} 2017$ & STSG & Bolster dressing & 5 days & No & No \\
\hline Hesse et al. ${ }^{[15]} 2019$ & STSG & Bolster dressing & $\begin{array}{l}\text { Not specified, mean LOS } 8 \\
\text { days so suspect some bedrest }\end{array}$ & No & No \\
\hline Erpelding et al. ${ }^{[34]} 2019$ & STSG & Bolster dressing & None & No & No \\
\hline Our practice & FTSG & Bolster dressing & None & $\begin{array}{l}\text { Apixiban } 2.5 \text { mg PO BID, } 30 \\
\text { days }\end{array}$ & No \\
\hline
\end{tabular}

STSG: split thickness skin graft; FTSG: full thickness skin graft; LOS: length of stay; VTE: venous thromboembolism; PO: "per os" or by mouth; BID: twice daily

have directly compared the two modalities. Of note, rates of graft take across series utilizing either bolster or VAC dressings have been excellent.

The need for penile skin grafting largely drives the length of hospital stay. Postoperative bed rest is often prescribed to prevent movement and sheer forces on the graft, which could disturb the earliest steps of graft take. The use and timing of bed rest after penile skin grafting in AABP has evolved greatly over time. Historically, bed rest was mandatory for up to 6 days postoperatively ${ }^{[2]}$, while more modern series have generally limited this time of immobility to $48-72 \mathrm{~h}^{[3,4,6,16,17]}$. Some groups still advocate 5 days of bed rest ${ }^{[22]}$. Table 1 shows the variability across series for intraoperative and postoperative care. We have adopted a "fast-track" approach to postoperative management of patients with AABP who require penile skin grafting. With a bolster dressing sutured in place, our patients do not require any bed rest. Patients generally ambulate early and discharge home on postoperative day 1 . Patients return to the office 4-6 days later for dressing, catheter, and drain removal. They continue daily dressing changes for 2 additional weeks at home. This practice has not resulted in noticeable detrimental effects on our graft outcomes.

\section{Surgical steps - escutcheonectomy/panniculectomy}

The importance of surgical resection of the mons fat pad, or escutcheon, for adequate treatment of AABP was first described by Horton et al. ${ }^{[9]}$ in 1987 . Shortly thereafter, Donatucci and Ritter ${ }^{[2]}$ published the first algorithm for the management of buried penis in adults that included resection of any impinging fat from the escutcheon and abdomen. Multiple variations in the approach to escutcheonectomy have been described. Some surgeons resect an ellipsoid ${ }^{[5]}$ or trapezoidal ${ }^{[22]}$ shaped specimen from the suprapubic fat pad, while others prefer to resect all penile and mons tissue and then bring the abdominal skin flap down to the base of the penis ${ }^{[3,16,26]}$ [Figure 3]. In our experience, this latter approach obfuscates the penopubic junction with an inferior edge of the panniculectomy skin flap meeting the proximal edge of the skin graft. This can sometimes lead to a divot particularly in the midline [Figure 4].

We favor leaving a 4- to 6- $\mathrm{cm}$ skin bridge at the superior base of the penis with as much viable proximal penile skin as possible, as suggested by other authors [Figure 5$]^{[6,14,22]}$. This bridge allows us to tack the skin at the base of the penis to the periosteum of the pubic symphysis, which re-creates the penopubic angle 




Figure 3. Intraoperative photograph showing abdominal and/or escutcheon skin flap approximated directly to the base of the penis

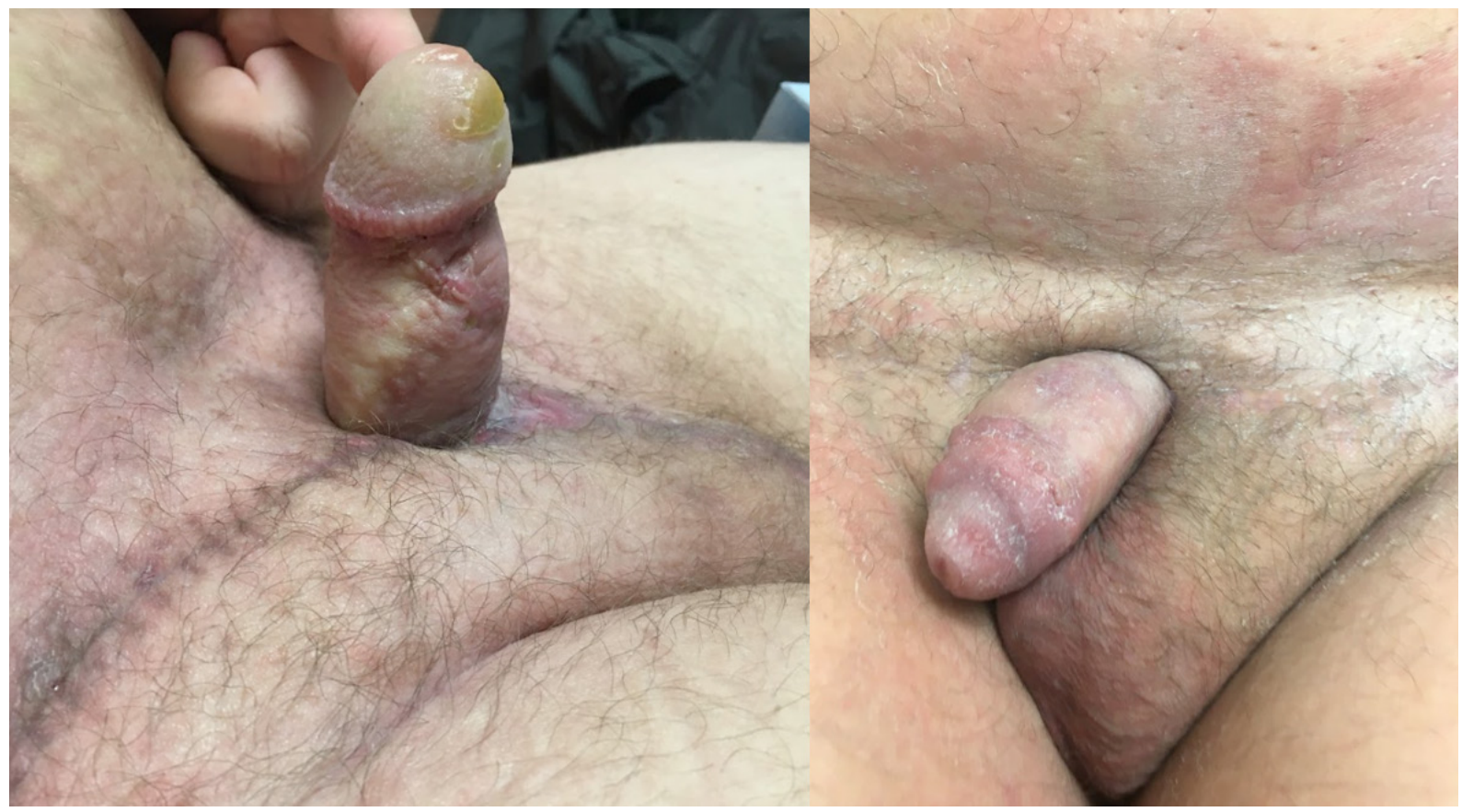

Figure 4. Post-operative images showing a divot or "moat" at the base of the penis

while also eliminating the need to approximate skin flaps to the base of the penis. Variations of the skinbridge have been previously described to improve contour and limit dog-ears in the mons region ${ }^{[27]}$. A critical step is to prevent a "moat", which is in the invagination of the proximal edge of the skin graft at 




Figure 5. Skin bridge at the base of the penis that can be tacked upwards to the superior skin flap to help reduce the possibility of divot formation by having an anastomosis at the base of the penis

the base of the penis [Figures 3 and 4]. This tends to occur when the skin graft is sutured in place with the penis on maximum stretch. The misconception is that grafting a stretched penis will result in improved unburied length post-operatively. On the contrary, this can lead to wound issues postoperatively due to retraction of the proximal graft into the surrounding skin, resulting in a persistently moist environment similar to that in the preoperative state [Figure 6].

One proposed solution was to create a "turtle-neck" ${ }^{[17]}$ by tacking the abdominal skin flap or remaining proximal penile skin a few centimeters distally on the penile shaft, which partially "re-buries" the penis, but prevents an invaginated moist edge. This invagination is especially prominent postoperatively when the patient is sitting or standing without an erection. A drain is placed underneath the escutcheonectomy skin flaps prior to closure to limit seroma and hematoma formation.

Abdominal panniculectomy is an adjunctive procedure during AABP repair in certain settings, and this should be done in conjunction with a plastic surgeon. This is typically necessary when the abdominal adipose tissue impinges on the penis directly. Thus, there is no delineation between the abdominal pannus and the (suprapubic) escutcheon (i.e., "single-bubble") [Figure 7]. Some prefer to obtain preoperative axial imaging to ensure that there is no concomitant abdominal wall hernia prior to panniculectomy in the setting of a massive pannus. Preoperative skin marking in the standing and sitting position can facilitate symmetry at the time of wound closure. It is our preference to perform panniculectomy in a wedge-shaped fashion taking care to avoid disruption of the lymphatics that run superficial to the abdominal wall fascia as much as possible; this can facilitate wound healing. During resection of the abdominal pannus, the umbilicus may need to be sacrificed but this does not negatively impact surgical outcomes. However, the patient must be counseled about this potential cosmetic alteration before surgery to ensure satisfaction with the postsurgical outcome. 


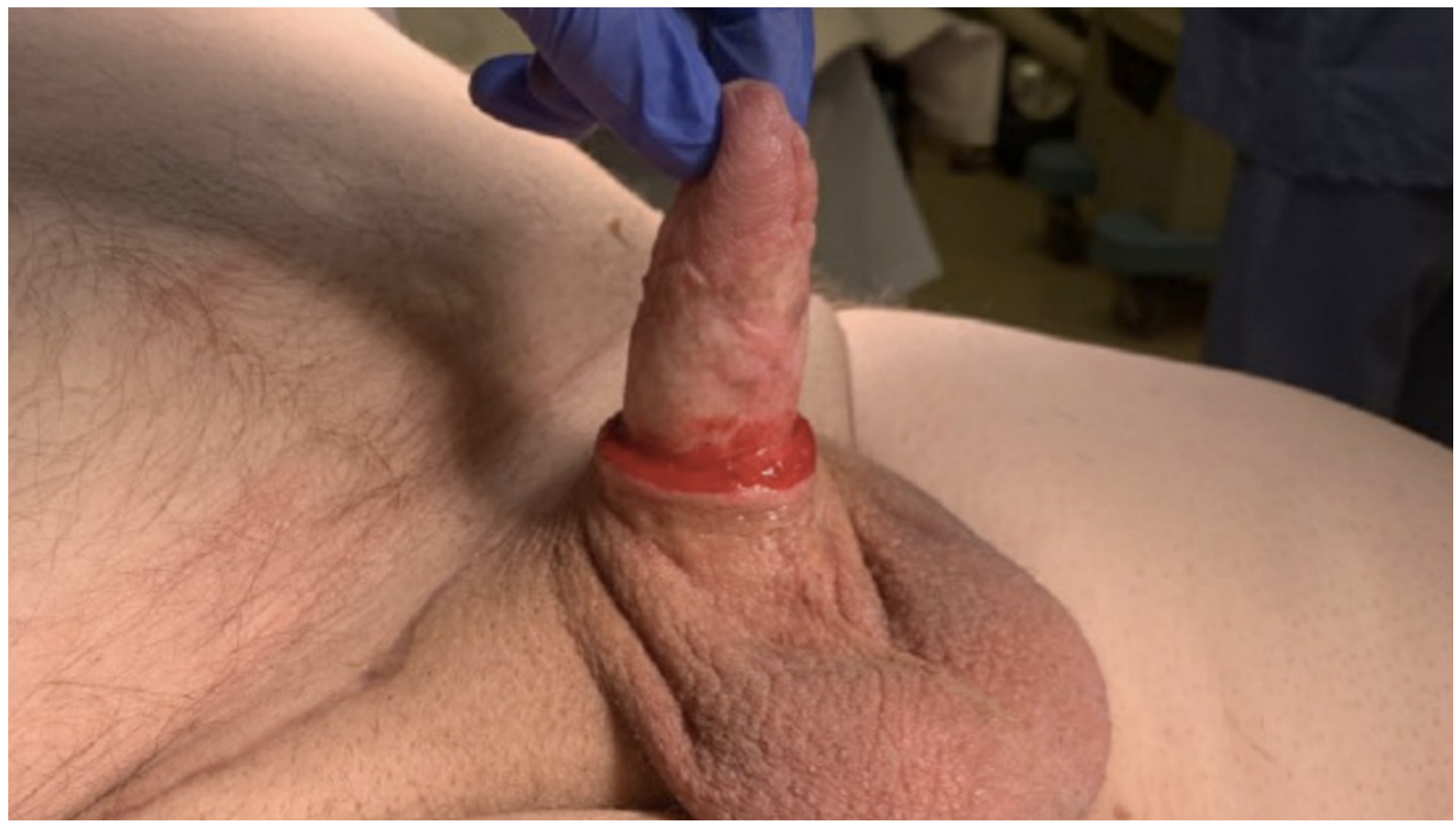

Figure 6. Chronic wound at the proximal aspect of the graft, where it was anastomosed to the native skin at the base of the penis. Must have penis on maximum stretch in supine position just to see entire graft and wound

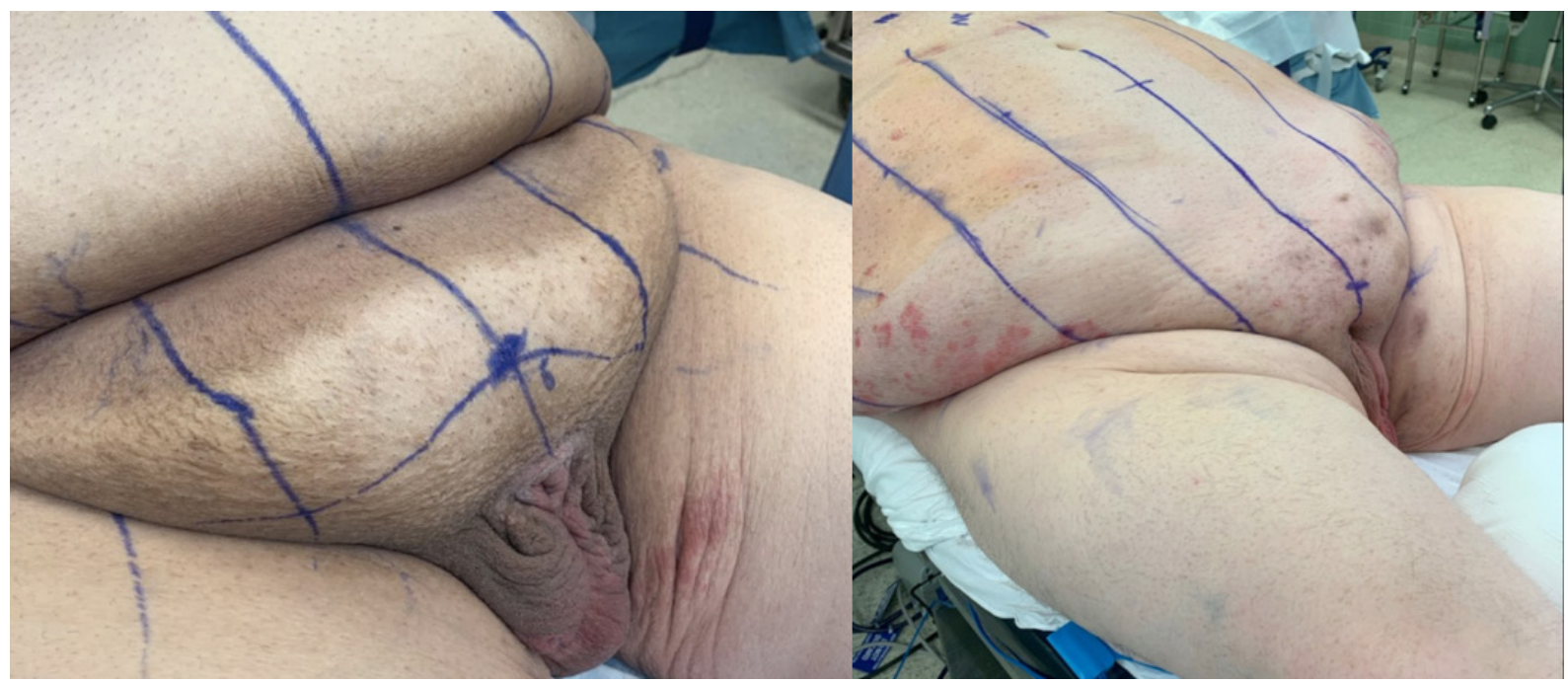

Figure 7. The first image is a patient with a separate abdominal pannus and escutcheon. The second shows a "single-bubble", no separation and direct impingement of the abdominal pannus onto the penis. The latter benefit is from plastic surgery involvement and panniculectomy

Drains are essential when patients undergo panniculectomy, as the increased potential space that is created during elevation of the abdominal wall flap puts the patient at a higher risk for seroma or hematoma formation. We generally place two large drains (19 Fr). Drains are removed once they have less than 30 milliliters per day output for multiple consecutive days. For abdominal panniculectomy patients, drains are sometimes required for weeks. We also require that patients who undergo panniculectomy wear an abdominal binder at all times for 4 weeks after surgery. 


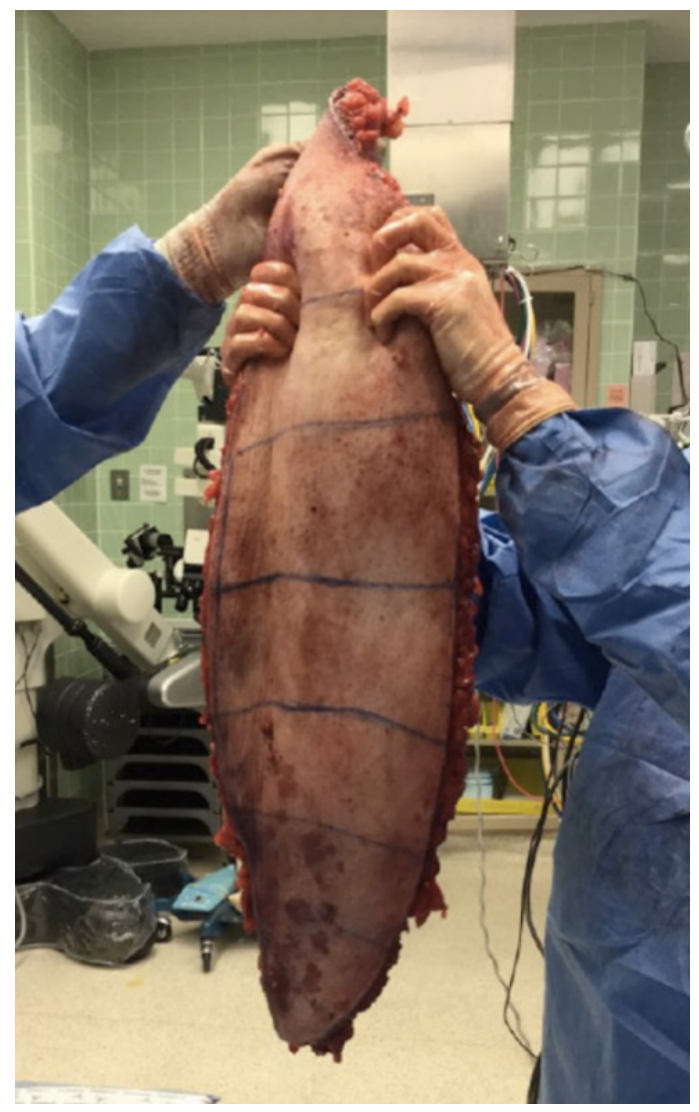

Figure 8. Large specimen of escutcheon adipose tissue. Skin can be harvested for penile skin grafting if needed

\section{Surgical steps - scrotectomy and scrotoplasty}

Buried penis for most patients in Western society can be ultimately attributed to obesity rather than genital lymphedema. Therefore, most patients have minimal scrotal involvement, which allows surgery to be performed in the supine position. This reduces the risk of positioning injury in a population already at high risk due to body habitus. For patients with scrotal lymphedema, we do perform surgery in the lithotomy position, so we can resect all diseased tissue. The posterior scrotal skin is usually uninvolved ${ }^{[28]}$ and can be used to help reconstruct the scrotum with the additional benefit of sparing the perirectal lymphatic supply. Another option is to place the testes in thigh pouches and close the perineum with local tissue flaps ${ }^{[15]}$, but we have preferred the cosmetic appearance of the reconfigured scrotum.

\section{Further sentiments regarding skin coverage}

While this was covered to some extent in the section "Release of the Buried Penis", we wanted to add a few more thoughts regarding penile skin coverage during AABP repair. We prefer to leave skin graft sizing and placement to the end of the procedure as the penile skin defect is only fully realized once the escutcheonectomy with or without panniculectomy incision has been closed, the penopubic angle reestablished, and the turtle-neck created.

There are a few choices to make when obtaining a skin graft during AABP repair. In most series, the graft is taken from the anterior thigh, which almost always has healthy skin. However, there is significant pain and scarring associated with a thigh graft harvest. Skin grafts can also be taken from a healthy portion of the escutcheonectomy specimen to eliminate donor site morbidity. We usually find that there is ample skin to allow for this [Figure 8]. 
If using the anterior thigh, split-thickness grafts are preferred given the inability to perform primary closure of the skin in this location. Our split-thickness grafts are usually 0.016 inch thick. If obtaining a split-thickness graft from an escutcheon specimen, anecdotally, it is easier to harvest prior to excision as retraction on a back table is very challenging.

\section{Our approach summarized - fast track AABP}

All patients are seen in the clinic and undergo a thorough history and physical examination. Moderate to severe obstructive voiding symptoms warrant preoperative cystoscopy or urethrogram to rule out urethral stricture disease, which is found in up to $47 \%$ of patients with $\mathrm{AABP}^{[13,29,30]}$. Management of urethral strictures in this population has been detailed previously ${ }^{[17,29]}$. Patients who are active smokers must quit at least 4 weeks prior to surgery. We check preoperative hemoglobin A1c on all diabetic patients to ensure adequate glycemic control. We note the duration of burying and whether or not the penis can be exhumed for examination. There is some concern about a potential association between buried penis and penile cancer $^{[31,32]}$, so this should be considered and evaluated in the clinic. In the setting of carcinoma, one may be able to palpate a firm, indurated mass along the penile shaft or glans. Preoperative imaging and biopsy are warranted in these cases. Biopsy can be performed cystoscopically (through the cicatrix) and/or using a core biopsy needle. Both are generally done in an operative setting. Lastly, we obtain preoperative CT scans for patients who require concomitant panniculectomy to rule out abdominal wall hernias. This also allows us to rule out any asymptomatic inguinal hernias that are difficult to palpate on examination due to obesity.

On the day of surgery, patients receive preoperative subcutaneous heparin prior to induction of anesthesia. They receive broad spectrum antimicrobials. Patients are placed in the supine position whenever feasible to reduce the risk of positioning injury associated with lithotomy. We use the LigaSure vessel sealing device for our abdominal panniculectomy resections, which decreases operative time and blood $\operatorname{loss}^{[33]}$. We leave as much healthy penile skin as possible as well as a skin bridge at the base of the penis which is tacked to the abdominal wall fascia. This re-establishes the penopubic angle and reduces issues with a "moat" as mentioned previously. The tacking of the skin bridge at the base of the penis is done using five to seven 0 PDS sutures. Some surgeons use permanent suture, but we do not find this necessary. We generally tack the dermis to the periosteum of the pubic symphysis. Great care should be taken to ensure a physiologic contour while avoiding the spermatic cords. Pitfalls of this tacking include: (1) sutures not adequately spread out (leading to a divot at the midline); (2) sutures tied too tight (also leads to a divot); and (3) sutures placed too close to the skin edge (prevents eversion of the inferior skin edge to meet the superior skin flap, resulting in wound healing issues). The abdominoplasty incisions are approximated over 1-2 closed suction drains with several layers of running absorbable sutures and skin glue.

A full-thickness skin graft is harvested from the escutcheon/pannus specimen to cover any penile skin defects. If the escutcheon skin is diseased, a split-thickness graft is taken from the anterior thigh. We prefer to use a sutured penile bolster dressing with a Foley catheter rather than wound VAC therapy [Figure 9]. Patients are instructed to ambulate and are discharged home on postoperative day 1 with their catheter, dressing, and drains in place. Subcutaneous heparin is continued in the hospital and transitioned to oral apixaban $2.5 \mathrm{mg}$ twice daily upon discharge for 1 month after surgery, since this population is at high risk for venous thromboembolism ${ }^{[13]}$. The dressings and drains are removed in the clinic 4-6 days after surgery if the drain output is less than 30 milliliters per day. Patients are taught to perform twice-daily dressing changes at home for an additional two weeks with Vaseline gauze and dry gauze. As we have transitioned to fast-tracking these patients, we have not noticed any worsening in our surgical outcomes or patient satisfaction. Another group recently published their positive experience utilizing outpatient (i.e., discharge on or before postoperative day 1) management of patients with AABP who underwent penile skin grafting $^{[34]}$. We suspect this will become the standard of care in the future. 


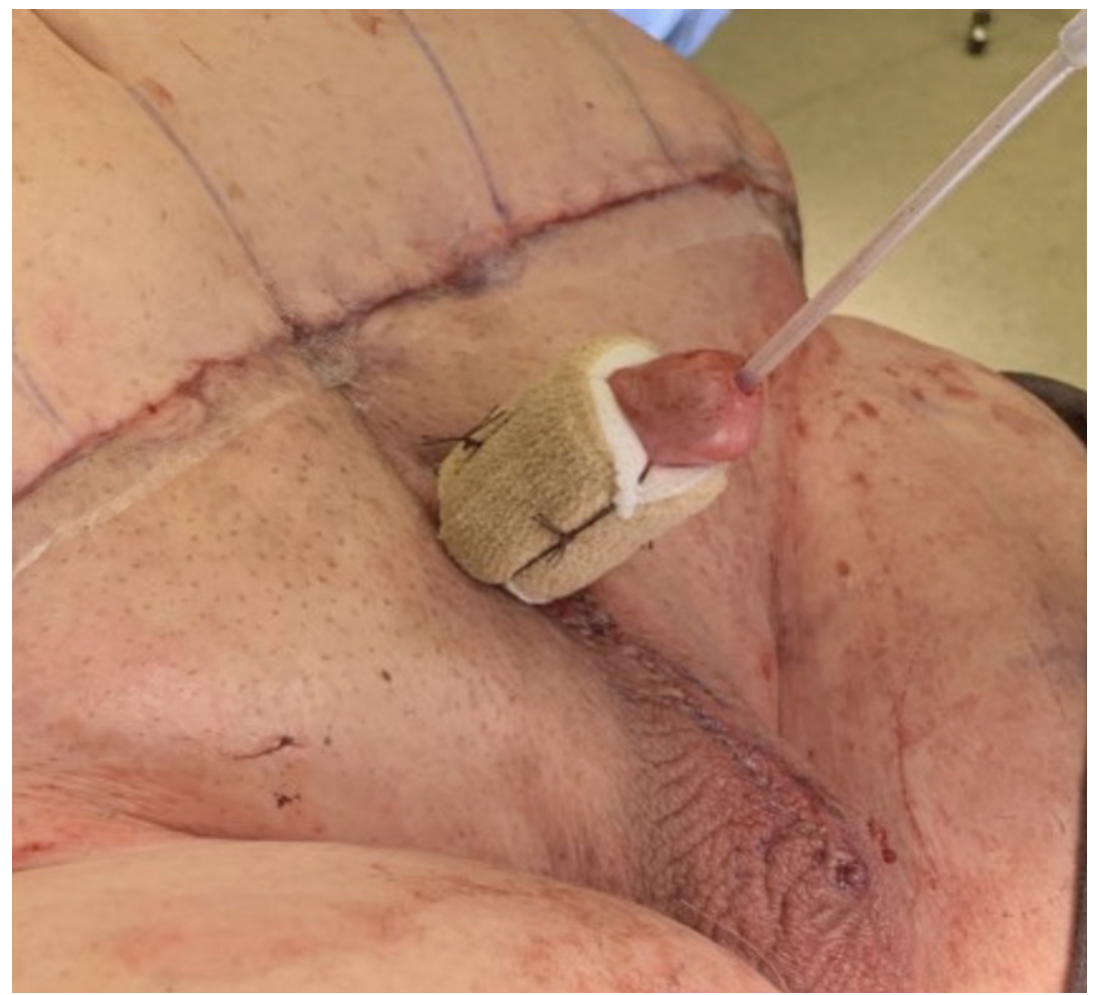

Figure 9. Bolster dressing protecting and immobilization of skin graft

\section{Surgical and quality of life outcomes}

Most series on surgical management of AABP to date have published outcomes that are focused on surgeons' objective measurements (penile length, graft take, successful unburying, etc.). The outcomes are highly favorable and have been described in detail in prior review articles ${ }^{[35-37]}$. These also highlight a relatively high rate of postoperative wound issues; however, it has been our experience that most of these can be managed conservatively with local wound care. Unfortunately, due to the complexity and comorbidities of the patient population, some of these wound complications can be devastating [Figure 10] and require surgical intervention or revision. When faced with a patient with a wound complication, recurrent burying, or aesthetic complaint, we strive to utilize conservative measures upfront and avoid reoperation until the tissues have completely healed (anecdotally, this can range from 4-8 months). Of note, when reviewing the literature on surgical outcomes after AABP repair, one must be aware that the surgical techniques, perioperative care, and the outcome measures deemed important vary largely from institution to institution, making comparisons across studies challenging.

Patient-reported quality of life (QOL) outcomes have been of interest more recently and show similar positive results. The first paper to suggest a potential detrimental effect of buried penis on QOL was a small case series from Detroit, Michigan, where all 5 patients treated for AABP had moderate to severe depression and 1 reported suicidal ideation ${ }^{[3]}$. Six years later, the first series focused on mental health and QOL outcomes was published ${ }^{[5]}$, which showed improvements in depression scores, health-related QOL and erectile function after surgical correction of AABP. Similar improvements in psychological wellbeing, urinary and sexual function, and overall QOL after surgery have since been reported by other groups $s^{[6,7,22,38,39]}$.

It is important to note that there is no validated QOL questionnaire dedicated to this condition, and that these series used various instruments including: modified post-bariatric surgery questionnaire ${ }^{[6]}$, the 


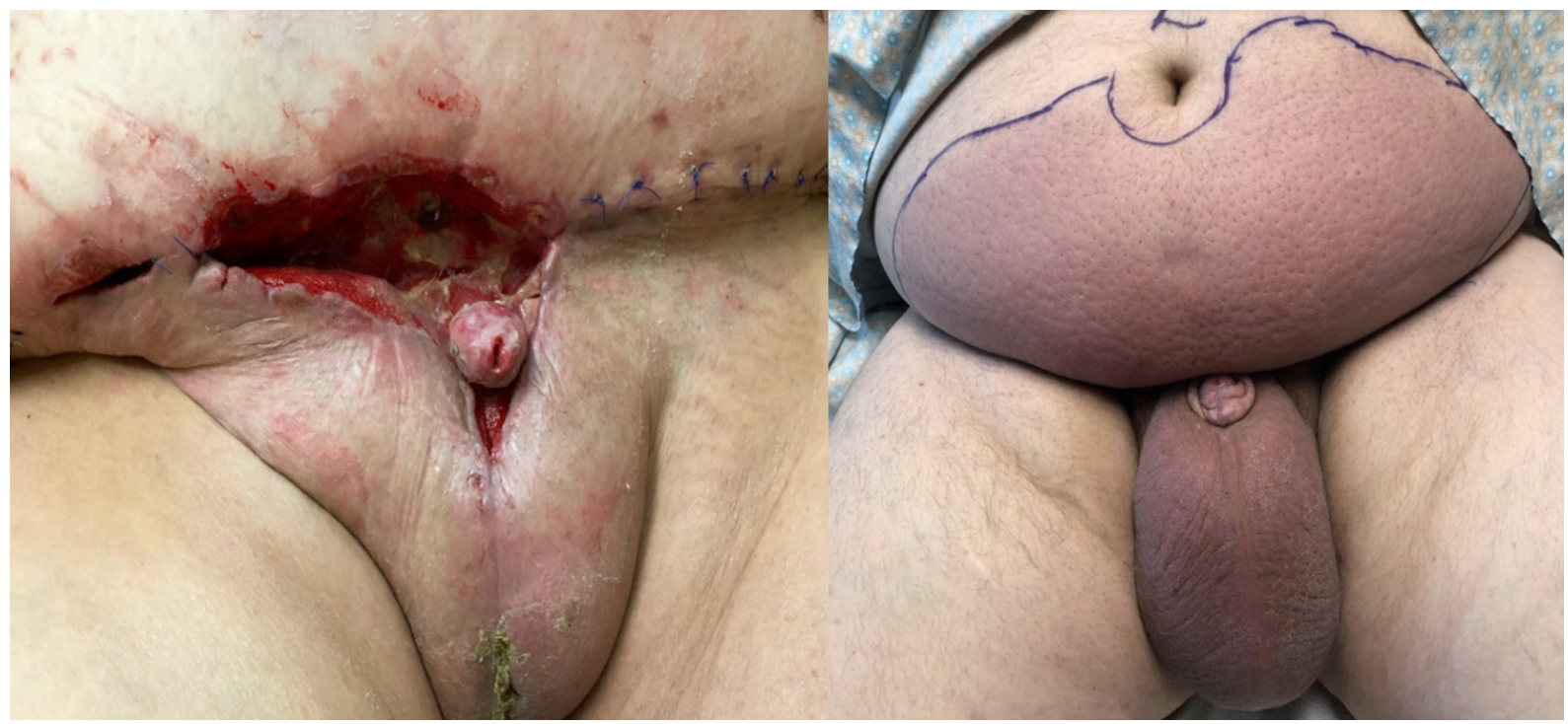

Figure 10. Significant wound complications including infection and breakdown

European Organization for Research and Treatment of Cancer 15 questionnaire ${ }^{[5]}$, the Expanded Prostate Cancer Index Composite questionnaire ${ }^{[7]}$, and the Changes in Sexual Functioning Questionnaire shortform $^{[38]}$. Furthermore, specific to sexual function and QOL, patients are often counseled that skin grafts should undergo innervation within approximately one year after surgery ${ }^{[19]}$, yet no studies to date have documented time to return of sensation of penile skin grafts

\section{Room for improvement}

There are many opportunities for improvement in the management of AABP. Efforts have been made to develop classification systems and surgical algorithms, as well as methods to ensure that our treatments are resulting in improvements in patient-specific QOL. However, there are several different classification systems published to date ${ }^{[13-15,40]}$ and thus, despite their similarities, fall short of allowing us to compare outcomes across series. Most series in the literature have fewer than 50 patients, highlighting the need for collaboration between institutions and centers of excellence to develop a universal classification system and treatment algorithm ${ }^{[41]}$. This would allow for comparison of results across studies and promote multiinstitutional research.

In addition, we need disease-specific QOL questionnaires and outcome measures to determine which surgical techniques result in the best functional and cosmetic outcomes. Understanding how surgery impacts long-term sexual function, penile sensory function with split- thickness and full-thickness skin grafts, and urinary function is critical to assist with honest preoperative counseling. We should evaluate the role of adjunctive measures such as phosphodiesterase inhibitors at improving graft take and limiting graft contracture $^{[39]}$. Head-to-head trials comparing different techniques would be ideal. Lastly, understanding the relationship between buried penis and penile cancer is necessary since many patients with this condition do not seek care for many years (if at all) because of embarrassment of their condition and/or unawareness of surgical options for repair.

\section{CONCLUSION}

$\mathrm{AABP}$ is a condition that is becoming more commonly seen by surgeons due to increased community awareness and overall prevalence. The main surgical steps to AABP repair include: release of the trapped penis and resection of diseased penile skin, escutcheonectomy/panniculectomy, scrotoplasty if needed, and 
penile coverage. The intricacies of the surgical technique are not universally agreed upon, and variation is widespread. It is difficult to optimize and generalize surgical approaches and postoperative care for this condition, as published reports often include few patients and fail to take into account patient satisfaction and QOL. The development of disease-specific QOL questionnaires and outcome measures will assist with future studies and improve the counseling of and care for patients with AABP.

\section{DECLARATIONS}

\section{Authors' contributions}

Made substantial contributions to conception and design and composition of the manuscript: Theisen KM, Pariser JJ

Contributed by data and photo gathering, and editing manuscript: Alford AV

Contributed by helping with revision of the manuscript and ensuring quality content and structure: Kim $\mathrm{N}$

\section{Availability of data and materials}

Not applicable.

\section{Financial support and sponsorship}

None.

\section{Conflicts of interest}

All authors declared that there are no conflicts of interest.

\section{Ethical approval and consent to participate}

Not applicable.

\section{Consent for publication}

Informed consent for use of perioperative images was obtained from the participants.

\section{Copyright}

(c) The Author(s) 2020.

\section{REFERENCE}

1 Hales CM, Carroll MD, Fryar CD, Ogden CL. Prevalence of obesity and severe obesity among adults: United States, 2017-2018. NCHS Data Brief, no 360. Hyattsville, MD: National Center for Health Statistics; 2020.

2 Donatucci CF, Ritter EF. Management of the buried penis in adults. J Urology 1998;159:420-4.

3 Tang SH, Kamat D, Santucci RA. Modern management of adult-acquired buried Penis. J Urology 2008;72:124-7.

4 Pestana IA, Greenfield JM, Walsh M, Donatucci CF, Erdmann D. Management of "Buried" penis in adulthood: an overview. Plast ReConstr Surg 2009;124:1186-95.

5 Rybak J, Larsen S, Yu M, Levine LA. Single center outcomes after reconstructive surgical correction of adult acquired buried penis: measurements of erectile function, depression, and quality of life. J Sex Med 2014;11:1086-91.

6 Voznesensky MA, Lawrence WT, Keith JN, Erickson BA. Patient-reported social, psychological, and urologic outcomes after adult buried penis repair. J Urology 2017;103:240-4.

7 Theisen KM, Fuller TW, Rusilko P. Surgical management of adult-acquired buried penis: impact on urinary and sexual quality of life outcomes. J Urology 2018;116:180-4.

8 Alter GJ, Ehrlich RM. A new technique for correction of the hidden penis in children and adults. J Urol 1999;161:455-9.

9 Horton CE, Vorstman B, Teasley D, Winslow B. Hidden penis release: adjunctive suprapubic lipectomy. Ann Plast Surg 1987;19:131-4.

10 Chopra CW, Ayoub NT, Bromfield C, Witt PD. Surgical management of acquired (cicatricial) buried penis in an adult patient. Ann Plast Surg 2002;49:545-9.

11 Dandapat MC, Mohapatro SK, Patro SK. Elephantiasis of the penis and scrotum. A review of 350 cases. Am J Surg 1985;149:686-90.

12 Malloy TR, Wein AJ, Gross P. Scrotal and penile lymphedema: surgical considerations and management. J Urol 1983;130:263-5.

13 Pariser JJ, Soto-Aviles OE, Miller B, Husainat M, Santucci RA. A simplified adult acquired buried penis repair classification system with an analysis of perioperative complications and urethral stricture disease. J Urology 2018;120:248-52. 
14 Tausch TJ, Tachibana I, Siegel JA, Hoxworth R, Scott JM, et al. Classification system for individualized treatment of adult buried penis syndrome. Plast Reconstr Surg 2016;138:703-11.

15 Hesse MA, Israel JS, Shulzhenko NO, Sanchez RJ, Garland CB, et al. The surgical treatment of adult acquired buried penis syndrome: a new classification system. Aesthet Surg J 2019;39:979-88.

16 Fuller TW, Theisen K, Rusilko P. Surgical management of adult acquired buried penis: escutcheonectomy, scrotectomy, and penile splitthickness skin graft. J Urology 2017;108:237-8.

17 Jun MS, Gallegos MA, Santucci RA. Contemporary management of adult-acquired buried penis. BJU Int 2018;122:713-5.

18 Zhao YQ, Zhang J, Yu MS, Long DC. Functional restoration of penis with partial defect by scrotal skin flap. J Urol 2009;182:2358-61.

19 Thakar HJ, Dugi DD. Skin grafting of the penis. Urol Clin North Am 2013;40:439-48.

20 King IC, Tahir A, Ramanathan C, Siddiqui H. Buried penis: evaluation of outcomes in children and adults, modification of a unified treatment algorithm, and review of the literature. ISRN Urol 2013;2013:109349.

21 Boonjindasup A, Pinsky M, Stewart C, Trost L, Chaffin A, et al. Management of adult concealed penis using a meshed, split-thickness skin graft. Can Urol Assoc J 2016;10:E407-11.

22 Hampson LA, Muncey W, Chung PH, Ma CC, Friedrich J, et al. Surgical and functional outcomes following buried penis repair with limited panniculectomy and split-thickness skin graft. J Urology 2017;110:234-8.

23 Monn MF, Socas J, Mellon MJ. The use of full thickness skin graft phalloplasty during adult acquired buried penis repair. J Urology 2019;129:223-7.

24 Morris MS, Morey AF, Stackhouse DA, Santucci RA. Fibrin sealant as tissue glue: preliminary experience in complex genital reconstructive surgery. J Urology 2006;67:688-91.

25 Weinfeld AB, Kelley P, Yuksel E, Tiwari P, Hsu P, et al. Circumferential negative-pressure dressing (VAC) to bolster skin grafts in the reconstruction of the penile shaft and scrotum. Ann Plast Surg 2005;54:178-83.

26 Strother MC, Skokan AJ, Sterling ME, Butler PD, Kovell RC. Adult buried penis repair with escutcheonectomy and split-thickness skin grafting. J Sex Med 2018;15:1198-204.

27 Blanton MW, Pestana IA, Donatucci CF, Erdmann D. A unique abdominoplasty approach in management of "buried" penis in adulthood. Plast Reconstr Surg 2010;125:1579-80.

28 Muller GP, Jordan CG. Elephantiasis Nostra. Ann Surg 1933;97:226-36.

29 Fuller TW, Pekala K, Theisen KM, Tapper A, Burks F, et al. Prevalence and surgical management of concurrent adult acquired buried penis and urethral stricture disease. World J Urol 2019;37:1409-13.

30 Liaw A, Rickborn L, McClung C. Incidence of urethral stricture in patients with adult acquired buried penis. Adv Urol 2017;2017:7056173.

31 Pekala KR, Pelzman D, Theisen KM, Rogers D, Maganty A, et al. The prevalence of penile cancer in patients with adult acquired buried penis. J Urology 2019;133:229-33.

32 Abdulla A, Daya D, Pinthus J, Davies T. Buried penis: an unrecognized risk factor in the development of invasive penile cancer. Can Urol Assoc J 2012;6:E199-202.

33 Siegel JA, Zhao L, Tachibana I, Carlson S, Tausch TJ, et al. Rapid excision of massive localized lymphedema of the male genitalia with vessel sealing device. Can J Urol 2016;23:8291-5.

34 Erpelding SG, Hopkins M, Dugan A, Liau JY, Gupta S. Outpatient surgical management for acquired buried penis. J Urology 2019;123:247-51.

35 Shaeer O, Shaeer K. Revealing the buried penis in adults. J Sex Med 2009;6:876-85.

36 Fuller TW, Theisen KM, Shah A, Rusilko PJ. Surgical management of adult acquired buried penis. Curr Urol Rep 2018;19:22.

37 Smith-Harrison LI, Piotrowski J, Machen GL, Guise A. Acquired buried penis in adults: a review of surgical management. Sex Med Rev 2020;8:150-7.

38 Hughes DB, Perez E, Garcia RM, Aragon OR, Erdmann D. Sexual and overall quality of life improvements after surgical correction of "buried penis". Ann Plast Surg 2016;76:532-5.

39 Cocci A, Cito G, Falcone M, Capece M, Maida FD, et al. Subjective and objective results in surgical correction of adult acquired buried penis: a single-centre observational study. Arch Ital Urol Androl 2019;91:25-9.

40 Mirastschijski U. Classification and treatment of the adult buried penis. Ann Plast Surg 2018;80:653-9.

41 Poore SO. The classification and surgical treatment of adult acquired buried penis syndrome: a call for data and collaboration. Aesthet Surg J 2020;40:NP83-4. 